\title{
O CONTRIBUTO DA GEOMORFOLOGIA PARA A COMPREENSÃO DA CONSTRUÇÃO DO ESPAÇO GEOGRÁFICO: BREVES REFLEXÕES
}

\author{
THE CONTRIBUTION OF GEOMORPHOLOGY TO UNDERSTANDING THE \\ CONSTRUCTION OF GEOGRAPHICAL SPACE: BRIEF REFLECTIONS
}

\section{LA CONTRIBUCIÓN DE LA GEOMORFOLOGÍA DE ENTENDER EL ESPACIO GEOGRÁFICO: BREVES REFLEXIONES}

\author{
António Souza Pedrosa - Universidade do Porto - Porto - Portugal \\ aspedros@gmail.com
}

\begin{abstract}
Resumo
0 primeiro objetivo da Geografia é explorar e explicar o espaço geográfico. A ciência moderna necessita de um corpo teórico, e não de uma obsessão de classificação, ou seja, existe a necessidade de um modelo epistemológico com o qual se defina teoricamente o seu objeto, trabalhe com conceitos e se estabeleçam leis. Para que se compreenda a posição atual do geógrafo, principalmente do geógrafo físico, é importante entender como se processou a evolução dessa ciência e quais os conceitos fundamentais pelos quais ela se rege. Neste trabalho discutem-se alguns problemas inerentes ao seu estatuto epistemológico, pretendendo-se contribuir para a compreensão de alguns conceitos e tendências evolutivas que estão na base da ciência geográfica, e mais especificamente da Geografia Física. Pretende-se, igualmente, destacar a importância da Geomorfologia na formação de base de um geógrafo, tendo como intenção provocar a reflexão e, ao mesmo tempo, suscitar uma tomada de consciência sobre a relação que existe entre a sua formação teórica fundamental e a sua atividade prática futura.
\end{abstract}

Palavras-chave: geografia, geomorfologia, epistemologia, conceitos, espaço geográfico.

\begin{abstract}
The first aim of Geography is to explore and explain the geographic space. Modern science requires a theoretical rather than an obsession with classification, ie, there is a need for epistemological models that defines the theoretical objects, work with concepts and establish laws. In order to understand the current position of the geographer and more specifically the physical geographer, it is important to understand, how is the evolution of this science and what the fundamental concepts by which it falls. In this paper we discuss some problems inherent in their epistemological status intend to contribute to the understanding of some concepts and changing trends, which are the basis of geographical science and more specifically of Physical Geography. The aim is also to emphasize the importance of geomorphology in the basic training of a geographer, and intended to provoke reflection and at the same time, raise an awareness of the relationship that exists between the fundamental theoretical and his future practical activity.
\end{abstract}

Key words: geography, geomorphology, epistemology, concepts, geographical space.

\section{Resumen}

El primer objetivo de la Geografía es explorar y explicar el espacio geográfico. La ciencia moderna tiene que desarrollar un modelo teórico-conceptual y no una obsesión con la clasificación. Así que hay una necesidad de desarrollar un modelo epistemológico que define su objeto de estudio, para desarrollar sus conceptos y establecer sus leyes. Para comprender la situación actual del geógrafo y más concretamente el geógrafo físico, es importante comprender su evolución, y cuáles son los conceptos fundamentales por los que se rige. En el presente trabajo se discuten algunos de los problemas inherentes a su epistemología, tengo intención de contribuir a la comprensión de algunos conceptos y tendencias evolutivas, que son la base de la ciencia 
geográfica y más concretamente de Geografía Física. Se pretende también destacar la importancia de la geomorfología en la formación básica de un geógrafo, con la intención de provocar la reflexión y al mismo tiempo, aumentar la conciencia de la relación entre la parte teórica y su actividad práctica.

Palabras clave: geografía, geomorfología, la epistemología, los conceptos, el espacio geográfico.

\section{Introdução}

O primeiro objetivo da Geografia é descobrir e explicar o espaço geográfico. Os tempos pré-científicos caracterizam-se por formas de exploração e de inventário, enquanto a ciência moderna necessita de um corpo teórico, e não de uma obsessão de classificação. Ou seja, existe a necessidade de um modelo epistemológico em que ela defina teoricamente o seu objeto, trabalhe com conceitos e estabeleça leis; a partir do momento que a lei estiver cientificamente provada pela teoria, passa-se à fase da verificação. É, assim, que se pode "verificar teoricamente as experiências", afirma Koyré, e não o inverso.

A Geografia, entendida como ciência da Terra e dos Homens, tem como objeto teórico o espaço; por conceito, a escala, a distância etc.; e por lei, por exemplo, a distribuição dos centros urbanos segundo uma hierarquia de serviços terciários. Essas leis explicam as configurações espaciais tipo e descrevem o funcionamento dos sistemas espaciais. A Geografia é, assim, indubitavelmente a ciência do espaço.

Para que se compreenda a posição atual do geógrafo, e mais especificamente a do geógrafo físico, é importante entender como se processou a evolução dessa ciência e quais os conceitos fundamentais pelos quais ela se rege. Neste trabalho discutem-se alguns problemas inerentes ao seu estatuto epistemológico, pretendendo-se contribuir para a compreensão de alguns conceitos e tendências evolutivas que estão na base da ciência geográfica e, mais especificamente, da Geografia Física. Pretende-se, igualmente, destacar a importância da Geomorfologia na formação de base de um geógrafo, tendo como intenção provocar a reflexão, e ao mesmo tempo suscitar uma tomada de consciência da relação que terá de existir entre a sua formação teórica fundamental e a sua futura atividade prática.

A construção do espaço geográfico: a dinâmica entre os fatores naturais e sociais

O trabalho quotidiano de geógrafo não consiste unicamente em teorizar ou determinar as leis do espaço, mas também em intervir nesse 
mesmo espaço para resolver os problemas que a sociedade lhe coloca. Não há prática sem conhecimento teórico. Perante essa perspectiva, a validade de um juízo advém da sua justeza teórica, assim como da sua eficácia para resolver os problemas espaciais, socioeconômicos e ambientais que a própria sociedade coloca. Para isso, ele consulta todos os indicadores disponíveis que possibilitam a compreensão da dinâmica do espaço geográfico: fotografias aéreas, imagens de satélite, documentos estatísticos e cartográficos e outras fontes, nomeadamente, históricas, arqueológicas etc.; elabora perfis topográficos, cortes geológicos, determina os perfis de alteração, reconstitui os paleoambientes etc.; por fim, deverá transmitir os seus resultados às instâncias políticas responsáveis pela gestão e ordenamento do território, de modo a que seja tomada uma decisão.

Apesar de o geógrafo, e principalmente do geógrafo físico, agir na prática mais como um naturalista do que como um teórico, essas ações nunca devem dissociar-se uma da outra. Se existirem regras de funcionamento do espaço, são essas leis que irão decidir, mas o geógrafo, na sua tomada de posição, tem de conhecer os princípios do sistema para compreender as dinâmicas espaciais que lhe estão associadas. Só desse modo as suas previsões e sugestões são socialmente úteis, já que possibilitam uma escolha à sociedade. É esta que comprovará, depois, a validade do trabalho do geógrafo.

No entanto, não se pode confundir investigação teórica e desenvolvimento do corpo teórico de uma ciência exclusivamente com a descrição matemática dos fenômenos ou com o desenvolvimento de modelos, erro que somos tentados a cometer demasiadas vezes. Deste modo, pensamos que não é necessário utilizar números para estabelecer uma teoria. Uma lei estatística é justa em estatística. Não passa de uma simples confusão quando se tenta afirmar que o fenômeno que ela tenta medir ou explicar é comandado por essa regra estatística. Pode ser que a regra estatística descreva, convenientemente, o aspecto do fenômeno que se pretende prever, mas é necessária uma grande dose de platonismo para considerarmos que estamos a desenvolver teoria, quando estamos apenas a descrever o objeto que a teoria procura analisar e compreender (Pech; Regnauld, 1993).

Já no século 21, Guillaume d’Okman (apud Pech; Regnauld, 1993) explicita bem o problema, ao afirmar que "o que é verdade num pensamento não é verdade da coisa pensada”. Apesar de um hidrograma de cheia ser teoricamente justo, o conceito de cheia não se altera só pelo fato de estar gráfica e estatisticamente representado. A cheia resulta da conju- 
gação de diversos fatores, cuja compreensão e previsão passa pelo domínio teórico do conhecimento da dinâmica fluvial, mas cujos efeitos não podem ser descritos pela lei em si, apesar de poderem ser avaliados pelo controle de especialistas.

A teoria tem de ser capaz de entender o espaço geográfico. Não pretendemos, no entanto, dizer com essa afirmação que o corpo teórico que a geografia vem desenvolvendo possui sempre razão, embora também não signifique que o aparelho matemático se mostre incompleto ou que a inteligência artificial esteja ainda nos seus primeiros passos. A questão que se coloca de uma forma clara é que o meio geográfico é construído por todas as sociedades e por todos os processos naturais. Dizer que o espaço possui leis que se regem por uma teoria é estabelecer que existem leis que a sociedade ou a natureza devem seguir para criar o espaço. É dar aos geógrafos que conhecem essas leis o enorme poder de dirigir a sociedade para mostrar-lhe o que ela deve fazer do espaço. É privar a instituição política do direito de planear o seu quadro de vida. É, por fim, um desvio platónico celle de roi géographe (Pech; Regnauld, 1993).

A ciência geográfica mede, utiliza as leis, elabora algumas para prever os efeitos dos diferentes processos, já que pensamos que é possível apreender teoricamente cada um dos processos e as suas inter-relações. Neste aspecto, a Geografia apresenta as características de uma ciência pura e dura. Pensamos, no entanto, que o conjunto de todos os processos e as suas inter-relações criam um espaço no qual o caos funciona como regra. O espaço não possui leis abstratas para opor-se ao trabalho dos homens. Ele não é senão uma construção submetida aos jogos sociais e ecológicos (ver Figura). O espaço é dinâmico, percorrido de fluxos de energia, de lutas, de poluições etc. Ele é produzido pelos processos sociais e naturais em interação.

Os processos podem, por sua vez, ser influenciados e muitas vezes modificados pela atuação do homem (erosão de solos, dinâmica fluvial, morfodinâmicas de vertente, comportamento dos elementos climáticos etc.), razão ainda mais forte para que a Geografia Física reforce a sua posição no âmbito da ciência geográfica. De fato, se a erosão é um processo natural, torna-se cada vez mais uma produção social (Neboit, 1979; Goudie, 1990; Muxart; Cosandey; Billard, 1990).

É segundo esse pressuposto que a geomorfologia é importante no contexto da ciência geográfica, já que os processos referentes à geodinâ- 
mica interna ou externa são, em parte, responsáveis pela dinâmica do espaço, razão por si só suficiente para que a Geografia não os possa ignorar.

Os processos morfogenéticos, para além de serem responsáveis pela evolução natural das formas de relevo, também são capazes de influenciar o comportamento das sociedades. Deste modo, tudo o que diz respeito às questões ambientais deveria ser sempre encarado, por nós humanos, de uma forma cuidadosa e sistemática, e como tal estudado com probidade, na perspectiva da realização do objetivo principal, que é a própria sobrevivência do homem, fato que, na prática, nem sempre acontece. E isto porque os problemas, em vez de serem encarados de forma global, visto que afetam toda a humanidade, em termos espaciais ou terrestres, intemporais, cósmicos ou universais, são considerados de modo limitado no espaço e no tempo, quase sempre com enorme egocentrismo, que se resume ao tempo restrito da vida da família, quando não pessoal (Cadoret, 1985; Klein, 1993; Geist, 2005).

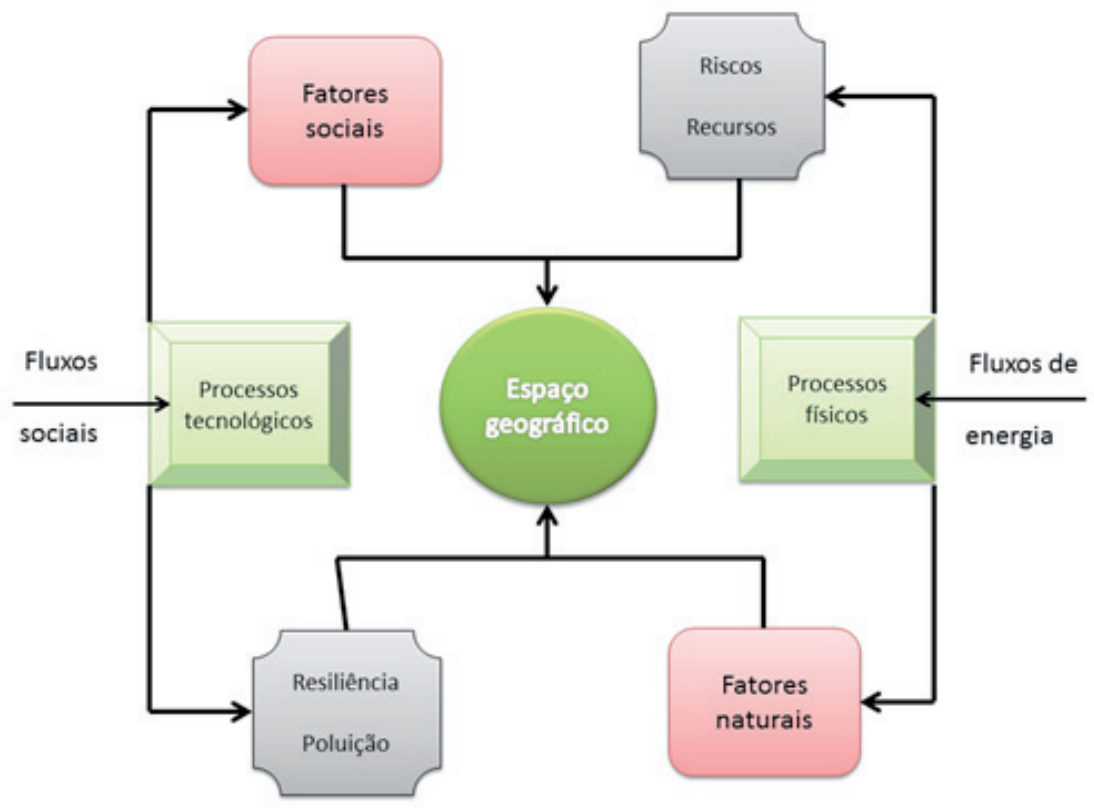

Figura: A produção do espaço geográfico

Fonte: Adaptado de Pech e Regnauld (1993). 
Essas duas concepções, globais ou abrangentes, localizadas ou restritas, distinguem duas perspectivas contraditórias de gestão do ambiente que, afastadas pela filosofia dominante na sociedade da Revolução Industrial, estão condenadas pelo próprio homem a caminhar para a reconciliação.

Pode-se, então, dizer que, até há poucos séculos, o comportamento da humanidade baseava-se numa perspectiva natural, sistêmica ou ecológica de perpetuidade, pouco dependente das intervenções do homem de então, que se pautava por um forte minimalismo e que não impunha alterações profundas à dinâmica natural. Só há pouco tempo iniciou-se outra fase, que se fundamenta numa intervenção profunda e cada vez mais ativa, de curto prazo, circunstancial e descuidada, e que deixou de ter em conta as regras ou os princípios naturais que se baseavam na identidade e na estabilidade e, como tal, na perpetuidade dos recursos do mundo em que vivemos. Hoje, apesar de ter aumentado a consciência ambiental, a maior preocupação continua a incidir no crescimento dos bens materiais de forma desenfreada, no aumento do lucro das empresas e no reforço das economias.

Nesta segunda fase, podemos afirmar que a intervenção agressiva do homem se caracteriza por criar desvios ou disfunções, de maior ou menor amplitude, os quais podemos considerar como as marcas recebidas por herança de gerações anteriores ou adquiridas por mutações relativamente circunstanciais. As causas mais frequentes relacionam-se ao regime alimentar, às deslocações cada vez mais frequentes, ao conforto material exagerado e luxuoso e às condições de trabalho em ambientes desgastantes e que, pelo cansaço físico e mental, levam à angústia que atinge o equilíbrio do sistema.

Nos dois últimos séculos, correlacionado com a filosofia judaico-cristã do norte da Europa, responsável pelo grande surto de tecnologia e crescimento material, a capacidade física de intervenção do homem no ambiente foi multiplicada por fatores tão elevados quanto imprevisíveis. Essa situação permitiu a revolução urbana e industrial e o aumento, até então inconcebível, da produção, do consumo e da riqueza de alguns, manifestada de uma forma individual ou mesmo estatal. Daqui resultaram formas de capitalismo neoliberais, ou então de capitalismo de Estado, extremamente predadoras, nomeadamente no que se refere aos recursos naturais e ao ambiente em geral, arrastando consigo novos problemas de 
ordem social. Compreende-se que, na situação de antagonismo Homem/ Ambiente, que se acentuou com esse novo modo de vida, tenham sido traçados caminhos cada vez mais divergentes e conflituosos entre os interesses do Homem e a sustentabilidade da Natureza. No Planeta Terra, tudo se interliga e a capacidade de recuperação e reciclagem do planeta, que até há bem pouco tempo se acreditava inesgotável, já demonstrou de forma evidente as suas limitações, começando-se a atingir em todo o sistema diversos pontos de ruptura (Guilhot, 1991; Bailly; Ferras, 1997; Neboit-Gutman, 2004).

Percebe-se, portanto, que o estudo das relações/interações entre as necessidades (ou exigências) do hóspede - o Homem, ao qual acabamos de nos referir - e as reservas dos materiais armazenados na dispensa da hospedaria ou do hospedeiro - a Terra - deveriam fazer parte dos vários níveis de ensino, com o intuito de divulgar o conhecimento, o que permitiria a sua assimilação e interiorização e, como tal, o respeito pela natureza e por todas as questões ambientais. Em não sendo assim, gera-se uma situação de conflito, decorrente do comportamento do elemento mais ativo e menos conformado, que é o hóspede, o que dificulta a manutenção do sistema em equilíbrio dinâmico que se desejaria perpétuo ou sustentável (Marsh; Grossa Jr, 2001; 2005). Hoje, apesar de a palavra "sustentável" fazer parte do léxico e dos discursos dos profissionais de economia e da política, não significa que as suas ações, atuações e decisões estejam em concordância com o seu significado.

O ambiente não pode ser reduzido a uma questão de poluição, ruído, resíduos sólidos, esgotos e de abastecimento de águas, como pretendem alguns negociantes do ordenamento, em nome do crescimento ou do urbanismo, em nome da modernidade ou da industrialização, ou em nome da criação ou da salvação de postos de trabalho. $\mathrm{O}$ ambiente deve ser encarado em toda a sua complexidade de conexões e inter-relações, e o homem, ao perseguir o seu ideal de uma melhor qualidade de vida, tem de compreender que só potenciando a diversidade (social, cultural, biológica, ambiental etc.) pode chegar a um desenvolvimento equilibrado, que conduza a uma maior valia da natureza e do próprio ser humano. O Homem, como agente da mudança na Natureza, cria a paisagem, dando-lhe forma, força, matéria e funcionalidade onde ela própria exige ser um espaço continuum de diversidade, combatendo, desta maneira, a sua própria simplificação e uniformização. A história da humanidade é, em larga medida, a 
história da nossa relação com a natureza empestada de mudanças, de crises, de paradigmas, de visões do Mundo que se foram sucedendo (Daveau, 1980; Veyret; Pech, 1993; Derruau, 1996; Defries; Asner; Houghton, 2004).

Nesta perspectiva, as estruturas biogeofísicas do espaço, como suporte em que se alicerça a construção do território, condicionam decisivamente as estratégias de implementação e desenvolvimento das atividades humanas. As características de ordem geológica, topográfica e geomorfológica, assim como as propriedades específicas dos solos, da rede hidrográfica e do clima em nível local e regional, constituem fatores determinantes da organização dos espaços de fixação humana e, como tais, dos espaços produtivos que constituem a base dos sistemas econômicos e sociais.

A crescente artificialização dos espaços de vivência das comunidades humanas incrementa a sua impreparação, exposição e vulnerabilidade em face dos diferentes tipos de fenômenos. Como tal, as relações entre o homem e a morfogênese deverão desenvolver-se segundo três pontos de vista: i) a consciencialização do homem do poder efetivo que possui sobre a evolução da morfogênese, fato que o deverá obrigar, definitivamente, a interrogar-se sobre a natureza das relações em nível de processos morfogenéticos elementares e das suas múltiplas combinações; ii) ao tomar conhecimento do funcionamento do sistema, o ser humano sente a necessidade de saber como as suas ações influenciam os fatores naturais e, daí, os processos morfogenéticos; iii a atuação que o homem exerce sobre a natureza não é uma entidade abstrata, antes pelo contrário, é uma realidade multiforme (Neboit, 1991).

A diversidade das situações regionais, sujeitas a riscos diferenciados, leva a que se questione se o equilíbrio natural pode ou não colapsar. Nessa desigualdade de tratamentos, coloca-se o problema da relatividade do peso dos fatores naturais e dos fatores humanos, ao mesmo tempo que é necessário encarar esse fenômeno sob diversas escalas temporais e espaciais (Neboit, 1991). A presença do homem na Terra é o resultado de um compromisso dinâmico entre as suas necessidades fisiológicas e culturais e a exploração dos recursos naturais existentes, mas a vida transcende largamente a espécie humana - que é, apenas, uma das espécies existentes, a mais recente e, porventura, uma das mais vulneráveis.

Ao longo da história do planeta, constata-se que o homem não é o primeiro ser vivo a modificar o meio ambiente ou a provocar variações 
nos elementos climáticos: há muitos milhões de anos, as algas marinhas modificaram profundamente a composição da atmosfera, liberando oxigênio, que constituiu um veneno letal para os microrganismos com metabolismo sulfuroso que existiam ao ar livre. Esse fato prova que a evolução progressiva, de efeitos cumulativos, mais cedo ou mais tarde atinge um ponto de ruptura, já que não existe na natureza crescimento contínuo acumulado. O mesmo pode acontecer com a ação do homem sobre a natureza se ele continuar, como nos últimos séculos, a exercer uma ação contínua e persistentemente agressiva sobre o ambiente, ao contrário da sua inicial posição, quando se pautava por métodos essencialmente defensivos na procura da sua própria sobrevivência (Pedrosa, 1997).

0 Conhecimento geomorfológico e sua importância para a manutenção do equilíbrio dinâmico dos sistemas terrestres

A geomorfologia, entendida como o estudo científico das formas de relevo da superfície da Terra, é sem dúvida, como diz Tricart (1965), uma das peças mestras da ciência geográfica. Assim, sempre que se procura uma completa explicação de qualquer forma da Terra, há que se fazer uma descrição da sua figura geométrica e compreender os processos envolvidos na sua gênese, bem como no seu desenvolvimento através do tempo.

No entanto, não basta a simples descrição das formas de relevo; é fundamental também o conhecimento das características climáticas da região em causa, bem como o conhecimento das características tectônicas, litológicas e biogeográficas, para compreender os processos morfogenéticos e, mais recentemente, a ação do homem, já que este terá de ser considerado cada vez mais como um agente geomorfológico ativo.

Assim, há de salientar-se a importância que os fatores estruturais, nomeadamente a tectônica e a litologia, possuem na formação e evolução das formas de relevo e, ainda, a sua influência na gênese e compreensão dos processos morfogenéticos (Feio; Brito, 1949; Blés; Feuga, 1981; Ollier, 1981; Pedrosa, 1993). Por exemplo, o fator litológico relaciona-se com a maior ou menor dureza das rochas, reflexo da sua origem e das suas características químico-mineralógicas. Deste modo, há determinadas formas que se relacionam sem qualquer margem para dúvidas com os diferentes tipos de rochas, tornando-se necessário conhecer o seu comportamento em função dos processos atuantes (Rebelo, 1975, 1991; Twidale, 1982, 
1989; Valadas, 1984; Romani, 1984; Godard, 1987; Cunha, 1988; Pedrosa, 1993; Ahnert, 1998).

Mas não se podem colocar à parte todas as interações que existem com o comportamento dos solos e com a vegetação, já que estes condicionam de forma indubitável a existência e o comportamento de diversos processos morfogenéticos (Guerra; Silva; Botelho, 1999; Drew, 1983; George, 1989; Brückner, 1986; Barrow, 2005, 2006). Acrescente-se, como já afirmamos, que a presença do homem e a sua ação sobre o território é cada vez mais um fator de instabilidade. Na verdade, essa ocupação pode ter dois aspectos distintos: i) sem uma interferência expressiva; ii) com uma intervenção significativa, cujas implicações alteram as próprias condições naturais de ocorrência de processos morfogenéticos. Por exemplo, a abertura de estradas ou a construção de outras estruturas na base nas vertentes é, sem margem para dúvidas, uma das práticas que mais alteram sua dinâmica, contribuindo para um forte desequilíbrio a montante da intervenção (Pedrosa, 1994, 2012a; Rebelo, 2003; Lambin; Geist, 2006).

O estudo do meio físico, como objeto geográfico, é cada vez mais importante e necessário ao próprio homem, já que sempre foi e continuará a ser o suporte das sociedades e das atividades humanas (Bailly, 1978; Pedrosa, 1994, 2012b, 2013; Slaymaker, 2000; Pereira; Pedrosa, 2012). O suporte físico do espaço geográfico tanto pode constituir-se em um risco como apresentar-se extremamente frágil. O seu estudo e, por conseguinte, a compreensão do seu dinamismo levam, certamente, a uma gestão mais racional e quiçá mais correta do território, cujo objetivo final será não só a previsão dos riscos, mas também o desenvolvimento de sistemas de prevenção julgados necessários para aumentar a resiliência da sociedade. Podemos citar como exemplo: i) a proteção das populações contra diferentes catástrofes naturais (sismos, fenômenos vulcânicos, ciclones tropicais, inundações, deslizamentos etc.); ii) a proteção das diferentes formas de poluição ou formas de degradação do meio natural, nomeadamente dos seus recursos naturais (Ramade, 1987; Rebelo, 1994, 2003; Bourrelier, De Vanssay; Deneufbourg, 2000; Strahler, 2001).

Entendidos dessa forma, todos os diferentes objetos geográficos são fenômenos que têm expressão no espaço. Deste modo, os meios naturais e os fluxos naturais são, então, objetos geográficos de corpo inteiro; constituem sistemas naturais auto-organizados (Bak; CHEN, 1991) e/ou caóticos, que se apresentam constituídos por elementos estáveis (litosfera, 
atmosfera, hidrosfera, biosfera, antroposfera); encontram-se em interconexão entre si, por meio dos fluxos de energia e de matéria; e instituem-se como os elementos dinâmicos caracterizados por forte instabilidade. Estão, ainda, organizados pela interconvergência de forças e de processos aleatórios e contraditórios, que podem levar a estádios momentaneamente equilibrados. É o caso das vertentes de montanha “ordenadas" pelo homem, que conhecem uma estabilidade aparente, apesar de um dado número de fatos e fenômenos, como o forte declive ou a precipitação elevada, mostrarem-se favoráveis à instabilidade.

Por outro lado, certos processos naturais possuem uma variabilidade periódica que se pode considerar normal (escoamento fluvial, marés etc.). No entanto, nessa aparente regularidade, podem surgir crises que conduzam a um comportamento caótico e desordenado da natureza - uma cheia, por exemplo. Podem existir, ainda, elementos que levem ao aparecimento de estádios críticos instantâneos, conduzindo a situações de risco grave. Estão nesse caso os sismos, os vulcões, os ciclones tropicais, entre outros.

A precisão com a qual se pode prever a evolução de um sistema dinâmico depende da precisão com que se conhecem as suas condições iniciais e as leis da sua dinâmica, fato que não é fácil de ser entendido por conta do funcionamento caótico do sistema (Gleick; 1987; Weber; DiGiano, 1996; Clini; Musu; Gullino, 2008). A ação do próprio homem modifica o funcionamento normal do próprio sistema, e, dado que a sua ação é agressiva e continuada, a dinâmica do meio sofre sucessivas alterações, por vezes difíceis de apreender e que implicam uma constante atualização do conhecimento no que se refere ao comportamento e funcionamento das dinâmicas espaciais. Assim, o que pode ser verdade hoje, pode não ser verdadeiro amanhã.

Deste modo, os estudos de geomorfologia mais recentes têm-se debruçado sobre o estudo dos processos morfogenéticos, procurando determinar quais os fatores que influenciam o seu aparecimento e, ainda, o desenvolvimento de modelos que levem à compreensão do seu funcionamento, tendo como objetivo prever as consequências que podem implicar (Birot, 1981; Godard; Rapp, 1987; Rebelo, 1988, 2003; Lourenço, 1988; Cooke; Doorrnkamp, 1990; Weber; Digiano, 1996; Marsh, 2010; Pedrosa; Pereira, 2011; Pedrosa; Rocha; Rodrigues, 2012). Deste modo, constata-se que esse objetivo fica a dever a diversas razões, que se prendem com os 
interesses puramente científicos, mas também com a aplicabilidade que o conhecimento geomorfológico pode ter para as questões do ordenamento do território (Pedrosa, 1997).

A razão principal relaciona-se indiscutivelmente com o próprio objeto de estudo desta ciência, ou seja, as formas da superfície da Terra (Pitty, 1971), entendidas como o resultado de uma dinâmica em que os intervenientes são múltiplos e as relações complexas. Depreende-se, então, que o estudo tem de possuir uma perspectiva morfodinâmica, na qual se interrelacionam as formas, os processos morfogenéticos passados, assim como aqueles que, atualmente, são responsáveis pela evolução das formas de relevo.

De fato, é importante conhecer como uma determinada área evoluiu no passado, pois esse conhecimento pode influenciar de uma forma muito direta a evolução atual (Pedrosa, 1993, 1994; Pedrosa et. al., 1997; Pedrosa; Martins, 2001, 2011; Eddy; Oeschger, 1993; Rebelo, 2001; Lambim; Geist, 2006). Também o conhecimento sobre como atuam na atualidade os diversos processos pode ajudar a clarificar a maneira como se processaram no passado. Na verdade, esses processos, hoje, apenas podem ser deduzidos pelas formas como originaram e pelos vestígios que deixaram. Tal como escreveu Rebelo (1981), é o estudo dos processos morfogenéticos atuais que possibilita o conhecimento do modo como evoluem as formas de relevo no seu conjunto e a uma escala suficientemente vasta. O seu estudo, todavia, tem de ser feito em uma escala cada vez mais pormenorizada, para conhecermos os seus vários aspectos e as suas implicações, principalmente no que diz respeito não só às construções humanas, mas também aos custos sociais e econômicos.

Trata-se, no entanto, de um trabalho complexo, já que um sistema morfogenético não se reduz a uma simples soma de processos elementares. É necessário concebê-lo numa perspectiva dinâmica, ou seja, como um sistema de inter-relações entre os processos dominantes e os não dominantes, segundo um jogo de fatores que eles próprios controlam (Tricart; Cailleux, 1965).

É esse tipo de relações que o geomorfólogo terá de identificar e conhecer para formular alternativas que possibilitem ao homem uma melhor utilização do território, quer nos aspectos de ocupação propriamente dita, quer no uso das técnicas que melhor se adequarem à sua exploração (Mahendrarajah; Jakeman; McAleeret, 1999; Fox, 2002). Assim, a geomorfologia pode contribuir para a manutenção do equilíbrio dinâmico respon- 
sável pela evolução natural das formas de relevo, evitando, deste modo, rupturas graves que ponham em causa o equilíbrio ambiental do sistema Terra, ou que representem situações de risco para o próprio homem.

\section{Conclusão}

Nessa perspectiva, a geomorfologia pode proporcionar uma reflexão séria sobre questões que continuam a fazer parte do nosso quotidiano, abrindo novos cenários científicos, culturais e sociais que proporcionem à sociedade uma visão diferente sobre o próprio o espaço em que se insere. Desta forma, é no ordenamento do território que o contributo da geomorfologia pode ter uma aplicação prática, colocando à disposição da sociedade o conhecimento teórico adquirido.

Se, de fato, entendermos o ordenamento do território como um conjunto de ações ou estratégias localizadas num dado espaço para otimizar sua utilização, então não se pode esquecer que esse espaço possui uma dimensão física. Assim, o ordenamento do território tem como base o conhecimento das formas de relevo e das características climáticas, hidrológicas e biogeográficas da região, objetos de estudo da Geografia. Por isso, sem embargo de encontrarmos o geógrafo numa fase adiantada dos trabalhos de ordenamento - de modo a distinguir as insuficiências e desequilíbrios de uma região, tendo em vista suprimi-las e modificar a paisagem -, teremos sempre de encontrá-lo na fase inicial, no momento da definição e compreensão dos suportes físicos (Rebelo, 1994).

A condenação sistemática das ações antrópicas sobre o meio não se justifica. O progresso que marcou o desenvolvimento das sociedades impôs-se mediante a apropriação da natureza e, sem dúvida, esse fato continuará a verificar-se. Apenas, no nosso entender, não é admissível a sua sobre-exploração e "gestão" incontrolada, como as gerações de um passado recente o fizeram e nós ainda continuamos a fazê-lo. As gerações vindouras terão necessidade da natureza para continuar a apoiar o seu desenvolvimento. Cabe à geração atual iniciar uma gestão controlada das ações sobre essa mesma natureza, no sentido de preservar ou recuperar o que ainda é possível, e, sobretudo, deixar definitivamente de agredir essa mesma natureza de forma tão destrutiva (Pedrosa, 1997).

Edgar Morin (1991) afirma que existe uma disjunção fundamental entre o homem e o mundo físico ou natural. O autor considera que o homem criou um estatuto de insularidade, tentando divorciar-se do seu 
suporte natural. É claro que tal situação é insustentável e a investigação geográfica deve, como já o vem fazendo, integrar nos seus estudos as relações homem-meio (Drew, 1983; Brückner, 1986; Slaymaker, 2000; Lambin; Geist, 2006; Pedrosa; Herrmann, 2007; Steiner, 2008).

O geógrafo deve estar preparado para entender as interações existentes na superfície da Terra (estrutura, litologia, formações superficiais, pedologia, hidrologia, ocupação florestal, ocupação agrícola, ocupação urbana, rede de transportes etc.) que levem à compreensão da importância das dinâmicas espaciais, de modo a poder identificar os problemas e interpretar as ocorrências em termos territoriais e temporais, a fim de formalizar hipóteses de intervenção sobre o espaço geográfico. Nesse contexto, o trabalho do geomorfólogo passa pelo conhecimento e desenvolvimento teórico que procura explicar as dinâmicas do suporte físico do espaço geográfico, ao mesmo tempo que deve definir estratégias de desenvolvimento e ocupação do território e produzir suportes gráficos e cartográficos com utilidade para o planeamento.

Estamos assim de acordo com Hulbert (1995), quando afirma que os geógrafos devem se envolver de uma forma clara com a comunidade em que se inserem, de forma que os trabalhos de pesquisa e de sindicância não faltem, mas que não podem parar no ponto onde se deveria iniciar a sua aplicação, fato que ocorre com demasiada frequência. Atribui-se aos detentores a decisão da quase exclusividade do uso desse saber, ou seja, o da aplicação dos resultados dos trabalhos do geógrafo. Naturalmente que cabe aos políticos o poder da decisão, mas esta não deve ser arbitrária nem o conhecimento que a geografia possui do território pode ser considerado "tabula rasa”. Os geógrafos devem, então, contribuir para o desenvolvimento de políticas alternativas, que fiquem à disposição da sociedade, possibilitando uma diversidade de escolhas entre as estratégicas de ocupação do território, tendo sempre em consideração o seu equilíbrio dinâmico.

Não existe disciplina melhor do que a Geografia para desvendar as inter-relações complexas natureza-sociedade, não somente para compreender, mas, sobretudo, para servir (Hétu, 2003). Para finalizar, e como afirmava uma afirmação de Hulbert (1995): "A Geografia pode medir as forças presentes e contribuir na modificação da relação de força que envolve o poder estabelecido, detentor tradicional da informação, e os cidadãos interessados". 


\section{Referências}

AHNERT, F. O. Introduction to geomorphology. London: J. Wiley, 1998.

BAILLY, A. L'environnementalisme, environnement et action. Paris: CNRS, 1978.

BAILLY, A.; FERRAS, R. Élements d'épistémologie de la Géographie. Paris: Armand Colin, 1997.

BAK, P.; CHEN, K. Les systémes critiques auto-organisés. Pour la science, n. 161, p. 52-60, 1991

BARROW, C. J. Environmental management and development. Routledge, 2005.

. Environmental management for sustainable development. New York: Taylor \& Francis, 2006.

BIROT, P. Les processus d'érosion à la surface des continents. Paris: Masson, 1981. BLÈS, J-L.; FEUGA, B. La fracturation des roches. Orléans: BRGM, 1981.

BOURRELIER, P. H.; DE VANSSAY, B.; DENEUFBOURG, G. Les catastrophes naturelles: le grand cafouillage. Paris: Osman Eyrolles Santé \& Société, 2000.

BRÜCKNER, H. Man's impact on the evolution of the physical environment in the Mediterranean region in historical times. Geo Journal, p. 7-17, 1986.

CADORET, A. Protection de la nature; histoire et idèologie, de la nature à l'environnement. Paris: L'Harmattan, 1985.

CLINI, C.; MUSU, I.; GULLINO, M. L. Sustainable development and environmental management: experiences and case studies. Berlin: Springer, 2008. .

COOKE, R. U.; DOORRNKAMP, J. C. Geomorphology in environmental management. An introduction. 2. ed. Oxford: Clarendon Press, 1990.

CUNHA, L. As Serras Calcárias de Condeixa-Sicó-Alvaiázere. Estudo de Geomorfologia. Dissertação (Doutorado em Letras) - Faculdade de Letras da Universidade de Coimbra, Coimbra, 1988.

DAVEAU, S. Espaço e tempo. Evolução do ambiente geográfico de Portugal ao longo dos tempos pré-históricos. Clio - Revista do Centro de História da Universidade de Lisboa, Lisboa, p. 13-37, 1980.

DEFRIES, R. S.; ASNER, G. P.; HOUGHTON, R. A. Ecosystems and land use change. Washington: American Geophysical Union, 2004.

DERRUAU, M. (Dir.). Composantes et concepts de la géographie physique. Paris: Armand Colin, 1996.

DREW, D. Man-Environment processes. London: George Allen \& Unwin, 1983.

EDDY, J. A.; OESCHGER, H. (Eds). Global changes in the perspective of the past. New York: John Wiley \& Sons, 1993.

FEIO, M.; BRITO, R. S. Les vallés de fracture dans les modèlé granitique portugais. Congrés Internationale de Geographie, Tomo II, Lisboa, p. 254-262. 1949. 
FOX, J. People and the environment: approaches for linking household and community surveys to remote sensing and GIS, v. 1, Springer, 2002.

GEIST, Helmut. Our earth's changing land: an Encyclopedia of Land-Use and Land-Cover Change. Portsmouth: Greenwood Publishing Group, 2005.

GEORGE, P. Les hommes sur la terre. Le géographie en movement. Paris: Seghers, 1989.

GLEIK, J. La théorie du chaos, vers une nouvelle science. Paris: Flammarion. 1987. GODARD, A. Pays et paysages du granite. Paris: PUF, 1977.

GODARD, A.; RAPP, A. Processus et mesure de l'érosion. Paris: CNRS, 1987.

GOUDIE, A. The human impact on the natural environment. 3. ed. Blackwell: Oxford, 1990. 388 p.

GUERRA, A. J. T.; SILVA, A. S; BOTELHO, R. G. M.(Orgs.) Erosão e conservação dos solos: conceitos, temas e aplicações. Rio de Janeiro: Bertrand Brasil, 1999.

GUTMAN, Garik. Land change science: observing, monitoring and understanding trajectories of change on the Earth's surface. v. 1, Springer, 2004. 459 p.

HULBERT, F. Le réveil des géographes? Cathiers de Géographie de Québec, v. 39, n. 108, décember, p. 497-508, 1995.

HÉTU, B. Uma geomorfologia socialmente útil: os riscos naturais em evidência. Mercator - Revista de Geografia da UFC, ano 2, n. 3, p. 83-97, 2003.

KIRKBY, M. J. Process models and theoretical geomorphology. New York: John Wiley \& Sons, 1994.

KLEIN, C. Du dynamisme des processus à la dynamique des formes en géomorphologie. Paris: Editions Ophrys, 1993.

LAMBIN, E. F.; GEIST, H. Land-use and land-cover change: local processes and global impacts. Berlin: Springer, 2006.

LOURENÇO, L. Efeitos do temporal de 23 de junho de 1988 na intensificação da erosão das vertentes afectadas pelo incêndio florestal de Argil/Oliveira de Hospital. Comunicações e conclusões do Seminário Técnico - Parques e Conservação da Natureza nos Países do sul da Europa, Faro, 1988.

MAHENDRARAJAH, S.; JAKEMAN, A. J.; MCALEERET, M. (Eds.) Modelling change in integrated economic and environmental systems. New Jersey: John Wiley \& Sons, 1999.

MARSH, W. M. Landscape planning: environmental applications. New Jersey: John Wiley Sons, 2010.

MARSH, W. M.; GROSSA Jr., L. Environmental geography: science, land use and earth systems. 2nd Edition. New Jersey: John Wiley \& Sons, 2001.

MARSH, W. M.; GROSSA Jr., J. Environmental geography: science, land use, and earth systems. New Jersey: John Wiley \& Sons, 2005.

MORIN, E. O método, v. 1. A natureza da natureza. Mem Martins: Publicações Europa-América, 1991. 
MUXART, T., COSANDEY, C.; BILLARD, A. L'érosion sur les hautes du Lingas: un processus naturel, une production sociale. CNRS, Paris. 1990.

NEBOIT, R. Les facteurs naturels et les factures humains de la morphogenèse. Essai de mise au point. Ann. Géogr. Alp., p. 649-670, 1979.

. L’Homme et l'érosion. L'érosion des sols dans le monde. 2e édition, Faculté $\bar{d} \overline{\text { es }}$ Lettres et Sciences Humaines de l’Université Blaise-Pascal. Clermont-Ferrand: Presses universitaires Blaise-Pascal, 1991.

NEBOIT-GUILHOT, R. Sociétés et risques naturels. De la gestion du risque à la mythologie. Bull. Assooc. Géogr. Fr., 3, Paris, p. 253-260, 1991.

O'CALLAGHAN, J. R. Land use: the interaction of economics, ecology and hydrology. Springer, 1996.

OLLIER, C. D. Tectonics and Landforms. London: Longman, 1981.

PECH, P.; REGNAULD; H. Géographie physique. Paris: PUF, 1993. (Coll. "Premier Cycle”)

PEDROSA, A. S. Serra do Marão: estudo de geomorfologia. Dissertação (Doutorado) - Faculdade de Letras da Universidade do Porto, Porto, v. 3. 1993.

. As actividades humanas e os processos morfogenéticos. O exemplo da Serra do Marão. Territorium, Coimbra, p. 23-34. 1994.

. Geografia física, ambiente e ordenamento do território, que perspectivas? Cadernos ESAP 1, Porto, p. 7-13, 1997.

A dinâmica geomorfológica das vertentes e suas implicações nas infraestruturas rodoviárias: alguns exemplos no Norte de Portugal. Geografia Ensino \& Pesquisa, v. 16, p. 71-81, 2012a.

. Montanha - um espaço historicamente construído: o exemplo das montanhas do Noroeste de Portugal. $2^{\circ}$ COLÓQUIO IBERO-AMERICANO DE PAISAGEM CULTURAL, PATRIMÔNIO E PROJETO - DESAFIOS E PERSPECTIVAS. Belo Horizonte: Ed. UFMG, v. 1. 20 p. $2012 \mathrm{~b}$.

. As montanhas do Noroeste de Portugal: uma paisagem cultural. Cosmos, Presidente Prudente, SP, v. 6, p. 7-67, 2013.

; HERRMANN M. L. P. Riscos naturais: interacção entre dinâmica natural e acção antrópica. Alguns estudos de caso no Norte de Portugal e no Sul do Brasil. Anais XII Simpósio Brasileiro de Geografia Física Aplicada - natureza, geotecnologias, ética e gestão do território. Natal, UFRN, Eixo 8 - Cidades e Regiões Metropolitanas: a Geografia frente aos problemas ambientais urbanos, p. 148-169, 2007.

; MARTINS, B. Os movimentos em massa e os depósitos de vertente em áreas metassedimentares: alguns exemplos no Norte de Portugal. Actas do II Seminário sobre Recursos Naturais, Ambiente e Ordenamento do Território. Vila Real: Universidade de Trás-os-Montes, v. 1, p. 161-169, 2001.

As formações superficiais no Norte de Portugal e suas implicações nos processos erosivos atuais. Geografia, Ensino \& Pesquisa, v. 15, p. 55-72, 2011. 
MTarão-' $-\bar{n}$-_-_; MARQUES, B.; SOUSA, J. Quaternary evolution of the Serra do 43, 2007.

; PEREIRA, A. A integração das formações superficiais na modelação e cartografia de risco geomorfológico: o caso da serra do Marão. Soc. \& Nat, Uberlândia, ano 23, n. 3, set./dez., p. 529-544, 2011.

PEREIRA, A.; PEDROSA, A. S. Paisagens agro-silvo-pastoris nos planaltos raianos da Meseta: reflexão sobre os condicionantes geomorfológicos do uso do solo. In: XIII COLÓQUIO IBÉRICO DE GEOGRAFIA: RESPUESTAS DE LA GEOGRAFÍA IBÉRICA A LA CRISIS ACTUAl, 2012. Santiago de Compustela: Unidixital, v. 1. p. 1707-1608, 2012.

PEDROSA, A. S.; ROCHA, E. A. V.; RODRIGUES, S. C. Proposta de modelagem da suscetibilidade à erosão laminar. Um estudo de caso na bacia do Ribeirão VaiVem (GO). Revista Geonorte, v. 2, p. 1707-1720, 2012.

PITTY, A. Introduction to Geomorphology. Londres: Methuen, 1971, 526 p.

RAMADE, F. Les catastrophes écologiques. Paris: McGraw-Hill, 1987. 403 p.

REBELO, F. Serras de Valongo. Estudo de geomorfologia. Suplementos de Biblos 9, Coimbra, 1975.

. Introdução ao estudo dos processos erosivos actuais na região do norte e do centro de Portugal. Revista da Universidade de Coimbra, 29, p. 85-95, 1981.

. A problemática da quantificação dos processos morfogenéticos. Alguns aspectos da contribuição da Escola de Geografia de Coimbra. Cadernos de Geografia, n. 7, Coimbra, p. 137-143, 1988.

. Geografia física e ambiente. Temas e problemas. Alguns casos concretos escolhìidos em Portugal. Cadernos de Geografia, Coimbra, n. 9, p. 85-95, 1991.

. Do ordenamento do território à gestão dos riscos naturais. A importância da Geografia Física salientada através de casos selecionados em Portugal. Territorium, Coimbra, p. 7-15, 1994. 2001. 274 p.

Riscos naturais e acção antrópica. Coimbra: Imprensa da Universidade,

. Riscos naturais e acção antrópica. Estudos e Reflexões. 2. ed. Coimbra: Imprensa da Universidade, 286 p. 2003.

ROMANI, J. R. Vidal - micromodelado de rocas graníticas. Un nuevo modelo genético. CONGRESSO ESPAÑOL DE GEOLOGIA, Actas I, Tomo I, Segóvia, p. 585-594, 1984.

SLAYMAKER, O. Geomorphology, Human Activity and Global Environmental Change. New Jersey: John Wiley \& Sons, 2000.

STRAHLER, A. H. Physical Geography: science and systems of the human environment. 2nd ed,, New York: John Wiley \& Sons, 2001.

STEINER, Frederick R. The living landscape: an ecological approach to landscape planning. Washington: Island Press, 2008. 
THOMPSON, R. D. Processes in Physical Geography. New York: Longman, 1986.

TRICART, J. Principes et méthodes de la Géomorphologie. Paris: Masson, 1965.

TRICART, J.; CAILLEUX, A. Introduction à la géomorphologie climatique. Paris: Sedes, 1965.

TWIDALE, C. R. Granite landforms. Amsterdam: Elsevier, 1982.

. La iniciación subsuperficial de las formas graniticas y sus implicaciones en las teorias generales de evolución del paisage. Cuaderno de Laboratorio Xeologico de Laxe, n. 13, Coruña, p. 49-68, 1989.

VALADAS, Bernard. Les hautes terres du massif Central Fançais. Contribution à l'étude des morphodynamiques récentes sur versants cristallins et volcaniques. v. I, II. Paris: Université de Paris I, 1984.

VEYRET, Y.; PECH, P. L'homme et l'environnement. Paris: PUF, 1993. (Coll. "Premier Cycle").

WEBER, W. J.; DIGIANO, F, A. Process dynamics in environmental systems. New York: John Wiley \& Sons, 1996.

António de Sousa Pedrosa - Possui graduação em Geografia pela Universidade do Porto. Possui Mestrado e doutorado em Geografia Física pela mesma Universidade Atualmente é Professor da Faculdade de Letras da Universidade do Porto e Professor visitante da Universidade Federal de Uberlândia.

Recebido para publicação em 12 de Agosto de 2014

Aceito para publicação em 23 de Outubro de 2014 